\title{
Ratiometric Sensor Based on PtOEP-C6/Poly (St-TFEMA) Film for Automatic Dissolved Oxygen Content Detection
}

\author{
Honglin Zhang ${ }^{1}$ and Zhiguo Zhang ${ }^{1,2, *}$ \\ 1 School of physics, Harbin Institute of Technology, Harbin 150001, China; zpp13125@163.com \\ 2 School of Instrumentation Science and Engineering, Harbin Institute of Technology, Harbin 150001, China \\ * Correspondence: zhangzhiguo@hit.edu.cn; Tel./Fax: +86-0451-8640-2639
}

Received: 29 September 2020; Accepted: 28 October 2020; Published: 29 October 2020

\begin{abstract}
A ratiometric oxygen sensor based on a platinum octaethylporphyrin (PtOEP)-coumarin 6 (C6)/poly (styrene-trifluoroethyl methacrylate) (poly (St-TFEMA)) film was developed for automatic dissolved oxygen (DO) detection. The oxygen-sensing film according to the dynamic quenching mechanism was prepared by embedding platinum octaethylporphyrin (PtOEP) and coumarin 6 (C6) in poly (styrene-trifluoroethyl methacrylate) (poly (St-TFEMA)). The optical parameter (OP) was defined as the ratio of the oxygen-insensitive fluorescence from $\mathrm{C} 6$ to the oxygen-sensitive phosphorescence from PtOEP. A calibration equation expressing the correlation between the $O P$ values and DO content described by a linear function was obtained. A program based on the Labview software was developed for monitoring the real-time DO content automatically. The influence of the excitation intensity and fluctuation on the $O P$ values and the direct luminescence signal (integration areas) was compared, verifying the strong anti-interference ability of the sensor. The detection limit of the sensor was determined to be 0.10 (1) $\mathrm{mg} / \mathrm{L}$. The switching response time and recovery time of the sensor were 0.4 and $1.3 \mathrm{~s}$, respectively. Finally, the oxygen sensor was applied to the investigation of the kinetic process of the DO content variation, which revealed an exponential relationship with time.
\end{abstract}

Keywords: ratiometric oxygen sensor; optical parameter; detection limit; DO kinetic process

\section{Introduction}

Oxygen is an essential element for the survival of human beings, animals, and plants, as well as for social development [1,2]. Oxygen content measurement is of great significance in environmental monitoring, clinical medicine, aquaculture, the food industry, and marine science [3]. In the food industry, the presence of dissolved oxygen (DO) directly affects the taste of beer and other products [4]. Serious water pollution due to organic pollutants [5] results in a lower DO value. The traditional Winkler titrimetric analysis method [6] and Clark electrode method [7] exhibit high accuracy in the measurement of DO content; however, the detection process is oxygen-consuming and seriously interfered with by external magnetic fields and organic solvents or gas $[8,9]$. To compensate for the deficiencies of the above two methods, researchers have developed optical oxygen sensors according to the principle of dynamic fluorescence quenching [10-12] for DO monitoring, which present excellent features including high sensitivity and accuracy, long-term stability, good anti-electromagnetic interference, and a lack of oxygen consumption $[13,14]$.

Currently, the widely used method for DO measurement is dependent on a single wavelength luminescence intensity, and is simple and easy to operate, accompanied by mature technology and testing instruments [15]. However, the detection signal can be seriously affected by the stability of the light source, probe concentration distribution [16], and optical path system [17]. In recent 
years, the ratiometric oxygen sensor $[18,19]$ based on a dual wavelength luminescence emission mechanism has been developed for accurate DO detection, receiving an increasing amount of attention. Ratiometric oxygen-sensing technology could overcome the issues caused by the single wavelength method, correct the influence of the probe concentration distribution, and eliminate the system error effectively [20,21]. Generally, the ratiometric oxygen sensor is immobilized an oxygen-sensitive indicator and an oxygen-insensitive reference indicator on appropriate matrix materials [19]. The structural design and performance optimization of the sensor is mainly dependent on the choice of indicators, the matrix, and their interactions. Chen et al. [22] prepared a ratiometric oxygen-sensing film by using $\mathrm{PtF}_{20} \mathrm{TPP}$ as the oxygen-sensitive probe and CdTe quantum dots as the reference probe, which can be applied for fast DO detection with a $0.5 \mathrm{mg} / \mathrm{L}$ detection limit. Zhao et al. [23] developed a ratiometric oxygen-sensing system based on phosphorescence from Gd-HMME and fluorescence from filter paper, which was limited to only gaseous oxygen detection owing to the irreducible pollution of the water environment that was evident with dissolved oxygen detection. Although much research has been conducted in recent years, the current oxygen sensor is still limited to single-factor detection. Thus, it is particularly important to develop an oxygen sensor with good oxygen-detection capability and strong anti-photo stability. Meanwhile, the sensor can be recycled, avoiding irreversible pollution of the measured environment.

In this study, we aimed to develop a PtOEP-C6/Poly(St-TFEMA) ratiometric oxygen sensor with high oxygen sensitivity, strong anti-interference ability, and accurate detection capabilities. Herein, PtOEP and C6 were selected as oxygen-dependent and oxygen-independent indicators, respectively. The optical parameter $(O P)$ was the ratio of the luminescence integral area of $\mathrm{C} 6$ to that of PtOEP, and the calibration equation between $O P$ and $D O$ is obtained The ratiometric oxygen sensor was developed based on the Labview software to achieve the automatic measurement of the DO content. The performance parameters including the detection limit, relative uncertainty, response time, fluctuations, and $O P$ stability were evaluated. Finally, the oxygen sensor was utilized for the study of the DO kinetics in water samples. The developed oxygen sensor can be expected to be applied in the fields of food fermentation and sewage treatment or biomedical field in the future by monitoring the change in oxygen content in real time, so as to achieve the accurate detection and strict control of oxygen content.

\section{Experimental Section}

\subsection{Materials}

Platinum octaethylporphine (PtOEP) and coumarin 6 (C6) were obtained from J\&K Chemical Co., Ltd., (Shanghai, China) and 2,2-Azobisisobutyronitrile (AIBN), Styrene (St), and trifluoroethyl methacrylate (TFEMA) were supplied by Alfa Aesar Co., Ltd., (Shanghai, China). Toluene was provided by Xilong Reagent Co., Ltd., (Shantou, China) Anhydrous magnesium sulphate $\left(\mathrm{MgSO}_{4}\right)$ was obtained from Tianjin Kermel Chemical Co., Ltd., (Tianjin, China). High-purity nitrogen and oxygen were purchased from Harbin Liming Co., Ltd., (Harbin, China). The AIBN was dried after re-crystallization from ethanol. The St and TFEMA were washed with $5 \% \mathrm{NaOH}$ to remove the inhibitor and dried with anhydrous $\mathrm{MgSO}_{4}$.

\subsection{Preparation of the Ratiometric Oxygen-Sensing Film}

The fluoropolymer of poly (St-TFEMA) was synthesized via the solvothermal method. First, the polymer precursor was obtained by dissolving a mixture of St (50 mmol), TFEM (50 mmol), and AIBN (1.0\% total mass of monomer) in toluene $(15 \mathrm{~mL})$. Then, the mixture solution was transferred into the reactor, and the polymerization reaction was allowed to proceed at $80^{\circ} \mathrm{C}$ and continuously stirred at $300 \mathrm{rpm}$ for $7 \mathrm{~h}$ under the protection of a nitrogen atmosphere. Next, the polymer solution was mixed with the PtOEP/toluene $(1 \mathrm{mM})$ and $\mathrm{C} 6 /$ toluene $(0.5 \mathrm{mM})$ indicator solution in a volumetric ratio of 10:1. Finally, the PtOEP-C6/Poly(St-TFEMA) ratiometric sensing film was obtained by casting 
the mixture solution onto quartz glass by using a four-side coating device (thickness controllable) and then stored in a dark place.

\subsection{Instruments and Characterization}

The ultraviolet-visible spectrum was used to study the absorption properties of PtOEP and C6. During the test process of UV-Vis absorption, a deuterium lamp was selected as the light source and an optical spectrometer (Ocean Optics QE65000) was the detecting device. The oxygen-sensing performance of the PtOEP-C6/Poly (St-TFEMA) ratiometric oxygen-sensing film was studied with a fiber-optic spectrometer (Ocean Optics USB2000, integration time $=100 \mathrm{~ms}$, average time $=20$ ) equipped with a diode laser centered at $405 \mathrm{~nm}$ as the excitation source. Furthermore, a nitrogen oxygen mixture device equipped with a gas flow-meter was used to obtain environments with different dissolved oxygen concentrations, and a commercial dissolved oxygen meter was used to calibrate the actual content.

\subsection{Automatic Ratiometric Oxygen-Sensing System}

A ratiometric oxygen sensor based on the Labview software was developed to achieve the automatic measurement of the DO content. Figure 1 shows the front panel of the ratiometric oxygen-sensing system.

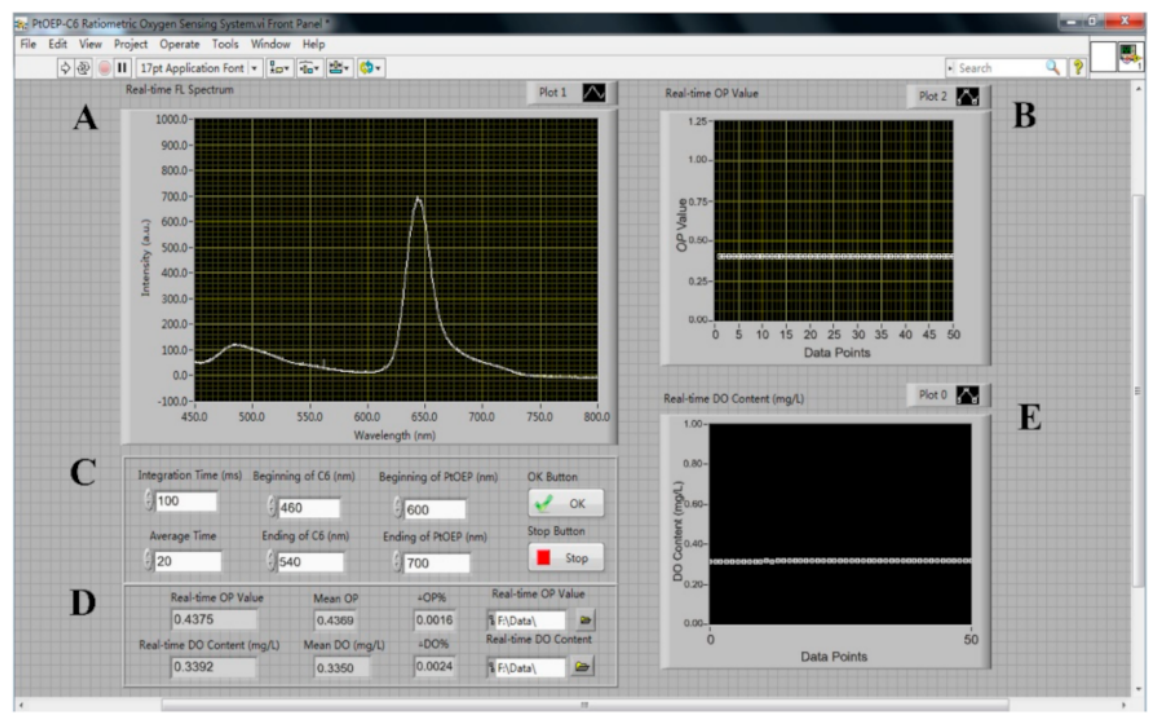

Figure 1. The front panel of the automatic ratiometric sensing system.

The program Panel Area A displays the online luminescence emission spectrum recorded by the USB2000 spectrometer.

Panel Area B exhibits the real-time $O P$ values.

The program Panel Area $\mathrm{C}$ is used to set the parameters including the integration time, average time, and beginning and ending wavelength of PtOEP and C6. Meanwhile, the OK and Stop buttons were used to start and shut down the system.

The program Panel Area D is for the file management and data analysis processes, displaying the real-time value and deviation value of the $O P$ and $D O$ content.

Panel Area E indicates the DO content calculated from the measured OP values combined with the $O P-D O$ calibration equation. 


\section{Results and Discussion}

\subsection{Optical Properties of PtOEP and C6 Indicator}

In this study, PtOEP was chosen as the oxygen-quenchable indicator and C6 as the reference indicator that was insensitive to oxygen. The typical normalized UV-absorption spectrum (PtOEP-black; C6-red) and luminescence spectrum (blue) of the PtOEP/toluene and C6/toluene solutions are presented in Figure $2 \mathrm{a}$ and were used to determine the maximum emission wavelength of the indicators. The UV spectrum indicates that PtOEP has a strong Soret band centered at $378 \mathrm{~nm}$ and two weaker Q-bands located at 499 and $534 \mathrm{~nm}$; C6 comprises a Soret band centered at $382 \mathrm{~nm}$ accompanied by four Q-bands located at 437, 454, 501 and $533 \mathrm{~nm}$. The excited state of PtOEP exhibits two phosphorescence emission peaks at 645 and $711 \mathrm{~nm}$. C6 has two strong fluorescence emission peaks at 484 and $510 \mathrm{~nm}$. The strong luminescence peaks at $645 \mathrm{~nm}$ of PtOEP and $484 \mathrm{~nm}$ of C6 were selected for the following study.
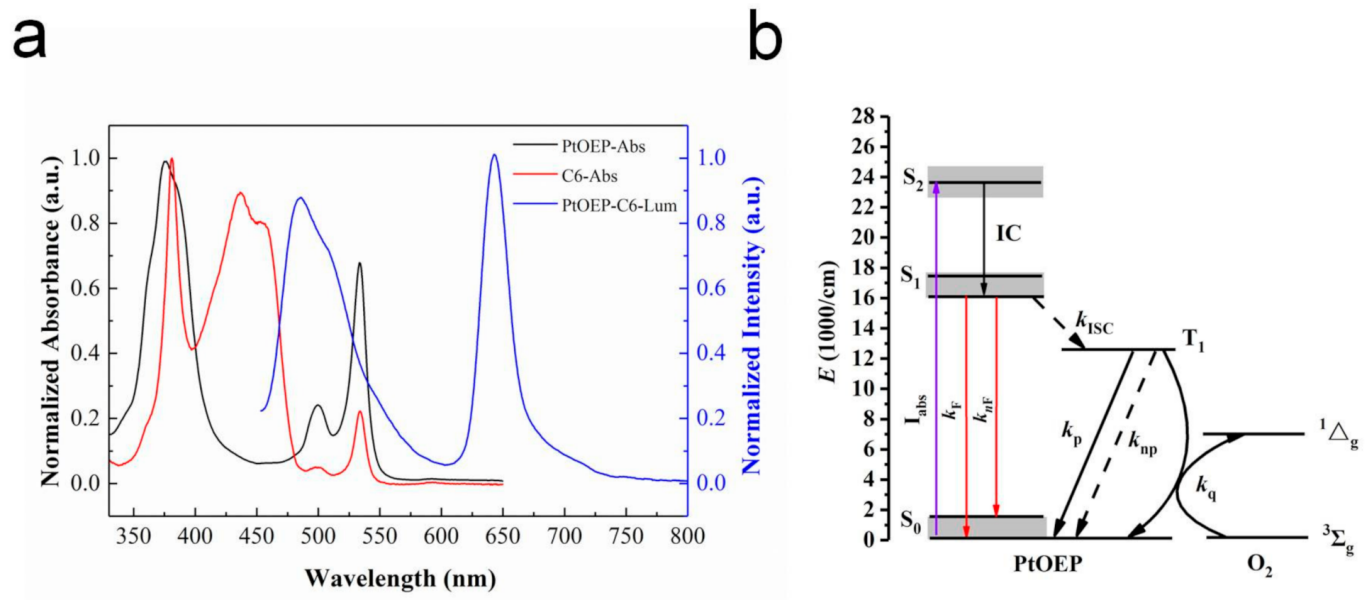

Figure 2. (a) Typical normalized UV-absorption spectrum (platinum octaethylporphyrin (PtOEP)—black; coumarin 6 (C6) — red) and luminescence spectrum (blue) of the PtOEP/toluene and C6/toluene solutions;

(b) The energy level structure of PtOEP.

Accordingly, the energy level structure of PtOEP is shown in Figure $2 b$. The particles of PtOEP in the ground state $S_{0}$ are pumped into the singlet excited state $S_{2}$, and then transferred to the excited state $S_{1}$ with lower energy through internal conversion (IC). The particles in $S_{1}$ return to $S_{0}$ via fluorescence emission $\left(k_{\mathrm{F}}\right)$ and non-radiative relaxation $\left(k_{\mathrm{nF}}\right)$; meanwhile, a certain number of particles reach the triplet excited state $T_{1}$ through Intersystem Crossing (ISC) [24,25]. However, $T_{1}$ to $S_{0}$ are transition forbidden; there are two energy transfer pathways for $\mathrm{T}_{1}$-state particles: returning to $\mathrm{S}_{0}$ by non-radiative relaxation and emitting phosphorescence. Phosphorescence quenching occurs when oxygen molecules exist in the surrounding environment, and the phosphorescence emission energy is plundered by oxygen molecules, which leads to the decay of the phosphorescence intensity or lifetime [23].

\subsection{Ratiometric Oxygen-Sensing Properties and the Calibration Curve}

The variation of the luminescence intensity of the PtOEP-C6/Poly (St-TFEMA) ratiometric sensing film with the DO content is shown in Figure 3. The phosphorescence intensity of PtOEP decreases dramatically with DO content, which indicates that the phosphorescence of the PtOEP-C6/Poly (St-TFEMA) film at $645 \mathrm{~nm}$ can be quenched by oxygen molecules effectively in the surrounding environment. Meanwhile, the reference indicator C6 exhibits a stable fluorescence signal at $484 \mathrm{~nm}$. Hence, the satisfactory ratiometric oxygen-sensing properties of the sample were verified. 


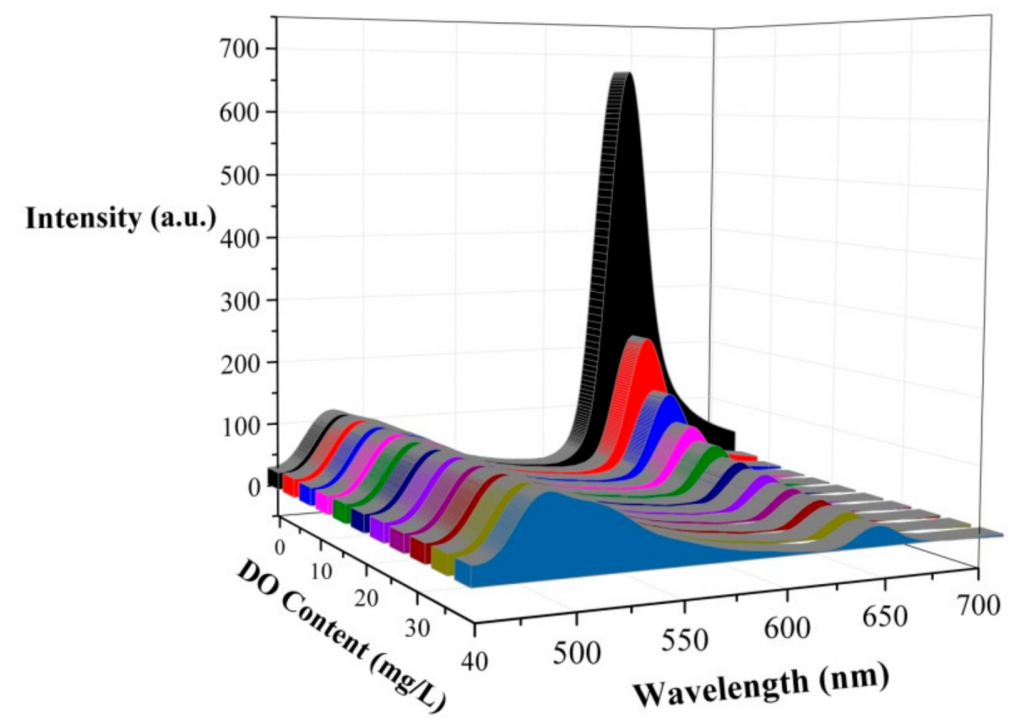

Figure 3. Variation in the luminescence intensity of the ratiometric sensing film with dissolved oxygen (DO) content.

Area 1 of C6, ranging from 460 to $540 \mathrm{~nm}$, was selected as the reference signal, and the integral area of $S_{1}$ was only proportional to the pump light intensity $I_{\text {pump }}$. Area 2 of PtOEP, ranging from 600 to $700 \mathrm{~nm}$, was the research signal, and the integral area of $S_{2}$ was not only related to the pump intensity $I_{\text {pump }}$ but also greatly dependent on the variation in the oxygen concentration. Herein, the optical parameter $O P$ was defined as $\mathrm{S}_{1} / \mathrm{S}_{2}$, which only related to the oxygen concentration $f\left(\left[\mathrm{O}_{2}\right]\right)$. Figure 4 presents the measured $O P$ value versus the increase in oxygen concentration, and the corresponding calibration curve is expressed as follows:

$$
O P=\mathrm{S}_{1} / \mathrm{S}_{2}=f([D O])=0.39+0.14[D O]
$$

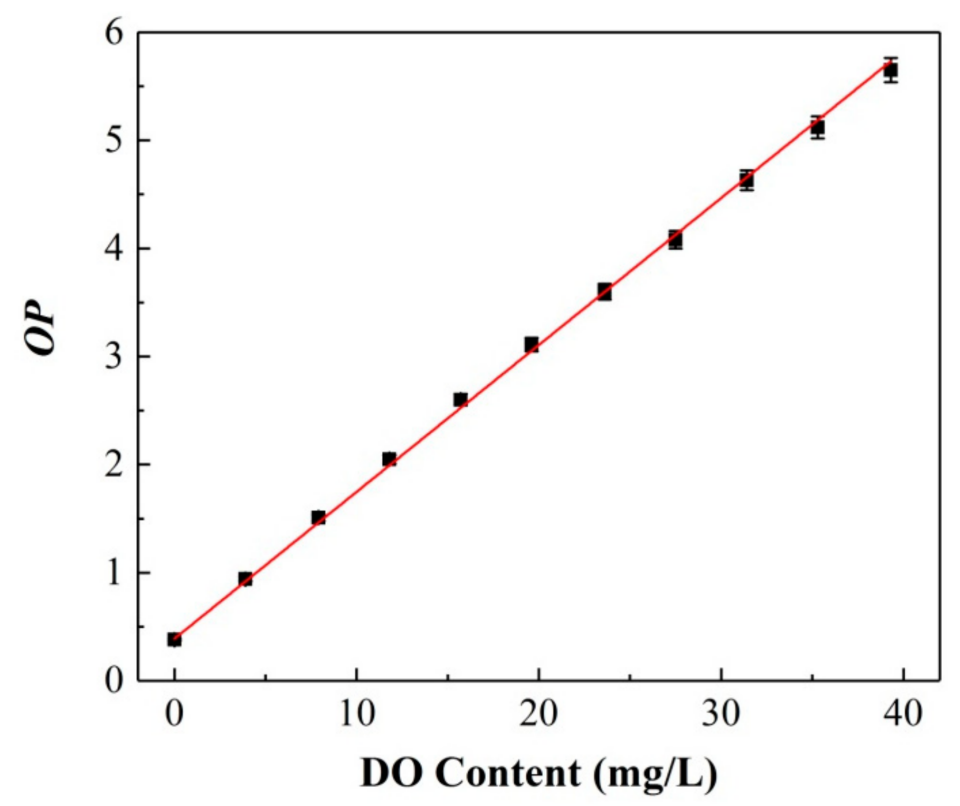

Figure 4. Calibration curve between the optimal parameter $(O P)$ value and $D O$ content of the ratiometric sensing film. 
It can be seen that the value of OP exhibits a correlation with the DO content described by a linear function Calibration standard deviation (RMSEC $=1.73 \%$ ). Moreover, all the data points were obtained by collecting 20 points in the same measurement process (the same later) to verify the repeatability of the calibration curve. Therefore, the DO content for any unknown sample can be calculated combined with the above calibration equation by measuring the $O P$ values.

\subsection{Anti-Interference Ability of the Ratiometric Oxygen Sensor}

Theoretically, the ratiometric method can effectively eliminate some interference factors during the testing process, such as the variation in the excitation light power density or the indicator concentration distribution [26-28]. To verify that the actual measurement value of the OP in this system was unrelated with the variation and fluctuation of the excitation intensity, the influence of the excitation power density $I_{\text {pump }}$ on the $O P$ values was investigated in detail. Figure 5 shows the variation in the $O P$ values, $S_{2}$ of PtOEP, and $S_{1}$ of $C 6$ versus the excitation light power density $I_{\text {pump. The test results }}$ indicate that the directly measured integration areas $S_{2}$ of PtOEP and $S_{1}$ of $C 6$ increase monotonously

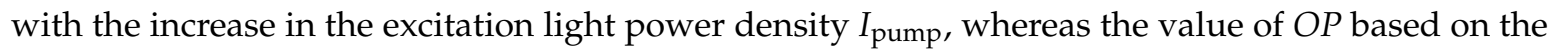

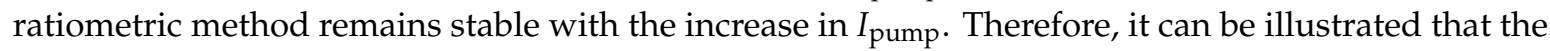
ratiometric oxygen sensor can effectively eliminate the interference of the variation of the excitation light during the measurement.

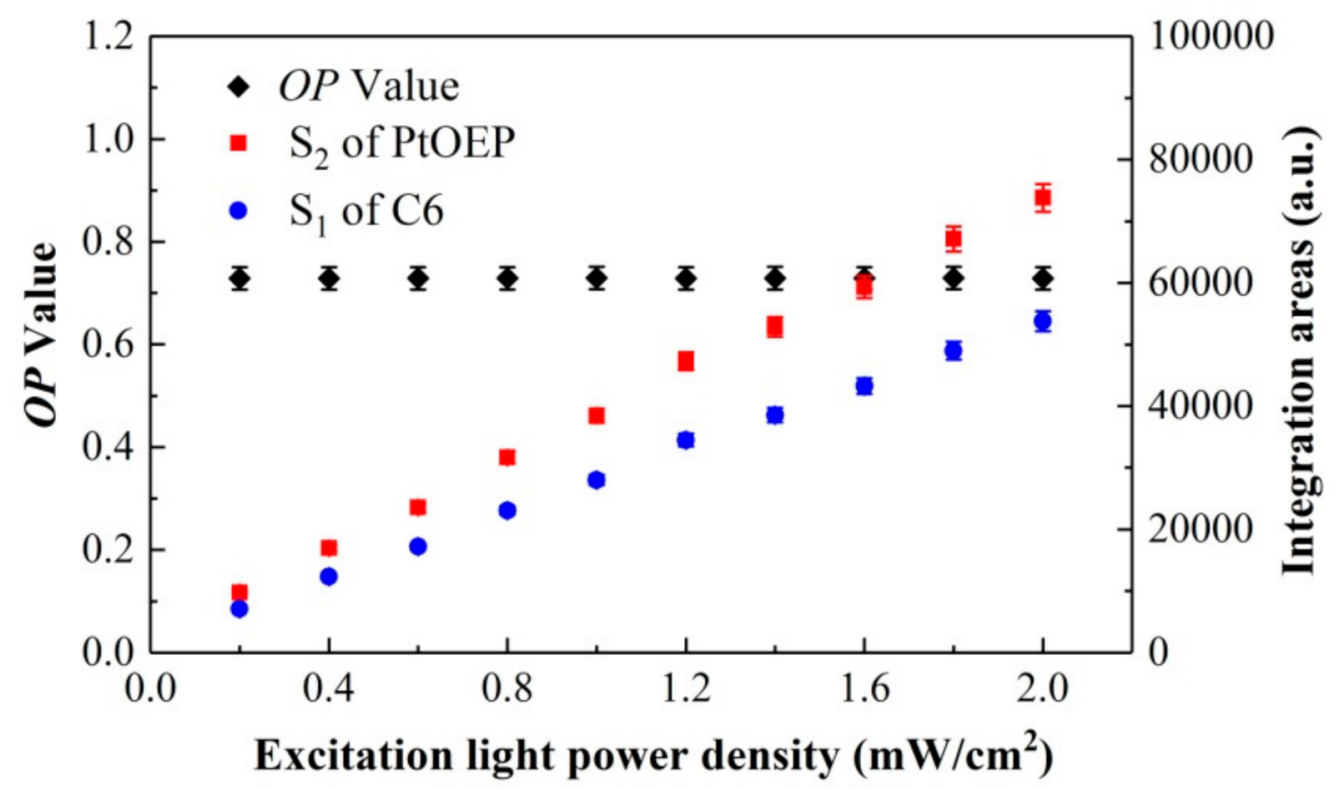

Figure 5. Variations in $O P, \mathrm{~S}_{2}$ of $\mathrm{PtOEP}$, and $\mathrm{S}_{1}$ of $\mathrm{C} 6$ versus excitation light power density.

Figure 6 shows the variation in the multiple measurement (100 times) values of $O P$, and the integration areas $S_{2}$ of PtOEP and $S_{1}$ of $C 6$ under $I_{\text {pump }}=0.4 \mathrm{~mW} / \mathrm{cm}^{2}$. As can be seen from the results, the measurement values of $O P(\sim 0.34 \%)$ were more stable, whereas the integration areas of PtOEP $(\sim 0.58 \%)$ and C6 ( 0.64\%) fluctuated with fluctuations in the excitation light significantly. This indicates that the ratiometric oxygen-sensing film can effectively eliminate the errors caused by the excitation light and fluctuation of the detector. 


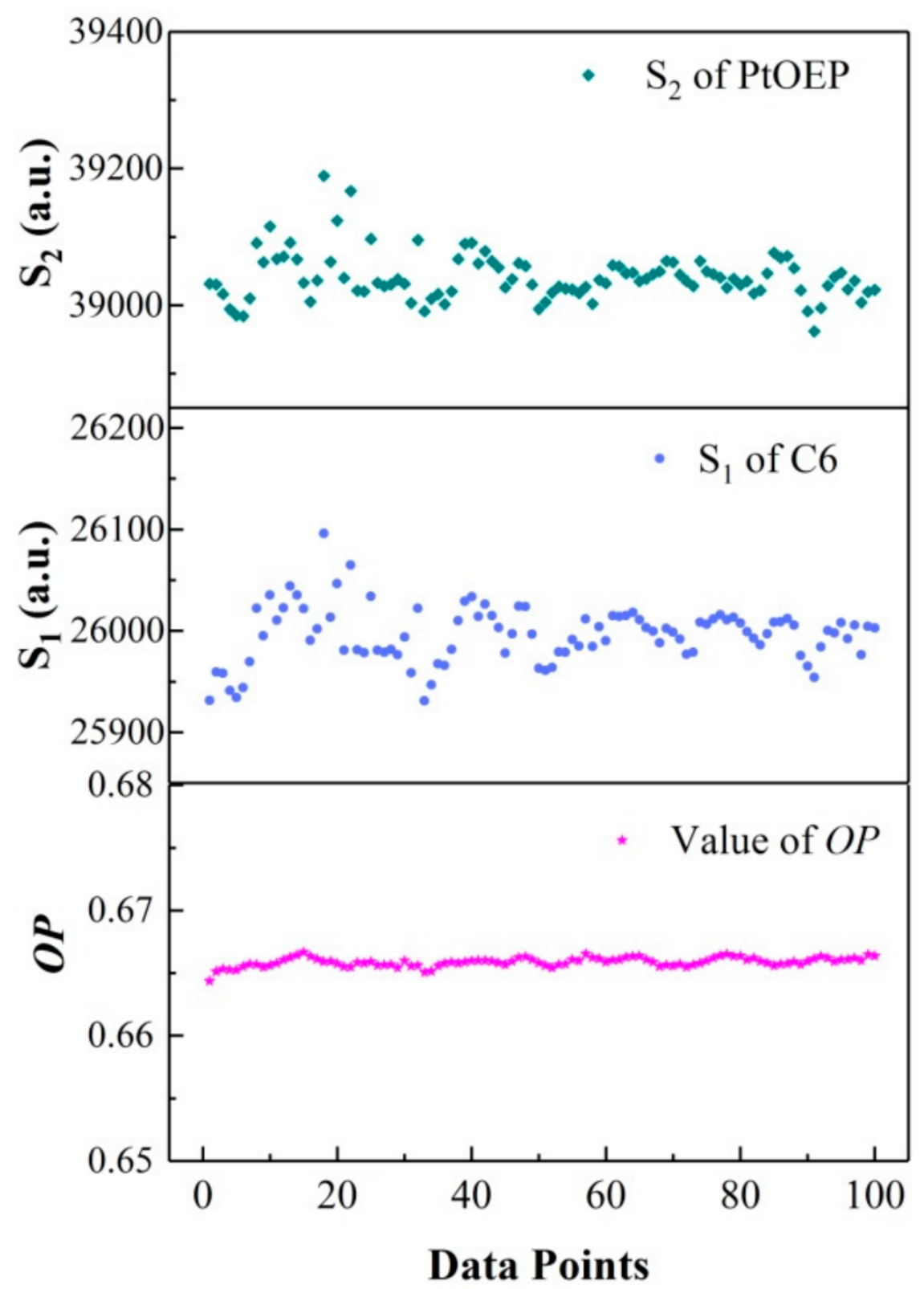

Figure 6. Variation in the values of $O P$, luminescence intensity of $I_{\mathrm{PtOEP}}$, and $I_{\mathrm{C} 6}$.

\subsection{Reversibility of the Ratiometric Oxygen-Sensing System}

The reversibility is an indication of the response time and reproducibility of the ratiometric oxygen sensor. The response time includes the quenching time $t_{Q}$ and recovery time $t_{R}[29,30]$, which represent the time required for a $95 \%$ change in the luminescence signal; $t_{Q}$ considers the change from an anaerobic to aerobic atmosphere, and $t_{R}$ considers the change from an aerobic to anaerobic environment [31]. Figure 7 shows the variation of the $O P$ value, and the response time of the film under the alternating conversion of the deoxygenation $(\mathrm{DO}=0 \mathrm{mg} / \mathrm{L})$ and oxygenation environment $(\mathrm{DO}=6 \mathrm{mg} / \mathrm{L})$. The results indicate that reproducible and stable luminescence signals can be obtained after testing for three cycles, and the sensor exhibits fast response times; $t_{Q}$ is $0.4 \pm 0.2 \mathrm{~s}$, while $t_{R}$ is $1.3 \pm 0.2 \mathrm{~s}$. 


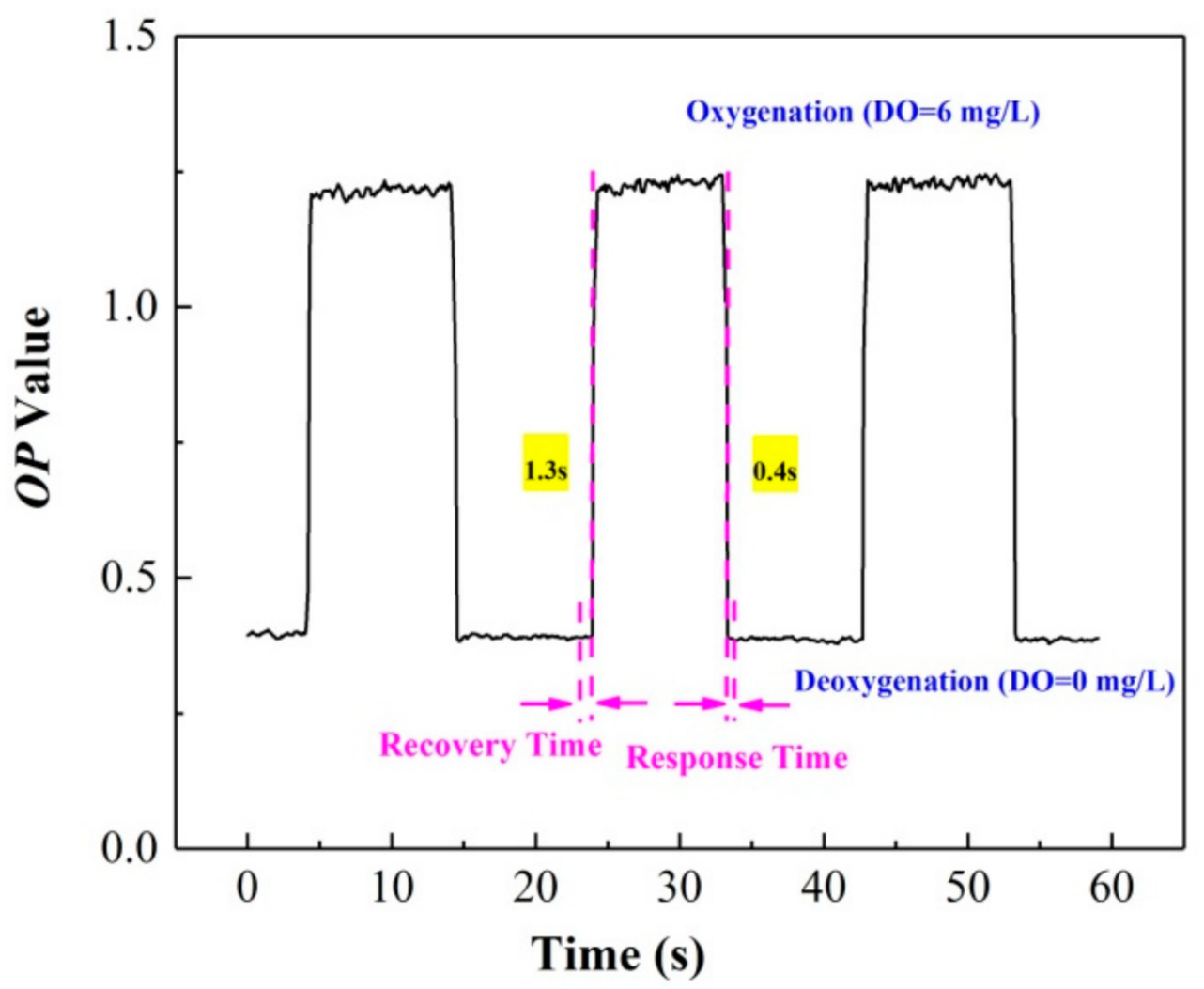

Figure 7. Reversibility and response time of the ratiometric oxygen-sensing system.

\subsection{Detection Limit of the Ratiometric Oxygen Sensor}

The detection limit (LOD) and relative uncertainty $(\Delta \mathrm{DO} / \mathrm{DO}) \%$ of the ratiometric oxygen sensor were obtained through further testing and analysis of the system. Samples with different DO concentrations were selected for multiple measurements. Herein, the LOD was defined as the oxygen concentration that brought the variation of the $O P$ value equal to the standard deviation [23]. The relative uncertainty of the oxygen-sensing system was obtained by analyzing and comparing the difference between the measurement results and real value, which was defined as half the value of the difference between the maximum and minimum values. Figure $8 \mathrm{a}$ shows the multiple measurements for different DO concentration samples. From the measured $O P$ values and combined with the calibration equation, the detected DO contents were $0.1,1.2,3.6,7.6,15.7$ and $39.3 \mathrm{mg} / \mathrm{L}$, respectively. The relative uncertainty during the test process was calculated as shown in Figure $8 \mathrm{~b}$. It can be seen that the relative uncertainty of the system increases with an increase in DO concentration, and the minimum uncertainty was $0.01 \mathrm{mg} / \mathrm{L}$, which appeared for a DO content of $0.10 \mathrm{mg} / \mathrm{L}$. Hence, the detection limit of the ratiometric oxygen sensor was further determined to be 0.10 (1) $\mathrm{mg} / \mathrm{L}$. For comparison, the detection limits and accuracy of different methods are listed in Table 1.

Table 1. Comparison of detection limit and accuracy of different methods.

\begin{tabular}{lcccc}
\hline No & Methods & Detection Limit (mg/L) & Detection Accuracy $\mathbf{( m g / L ) ~}$ & Reference \\
\hline 1 & Winkler method & 0.19 & 0.02 & {$[32]$} \\
2 & Clark electrode method & 0.1 & 0.1 & {$[1]$} \\
3 & $\begin{array}{c}\text { Dual emission based on } \\
\text { PtF20TPP-CdTe film }\end{array}$ & 0.5 & 0.5 & {$[22]$} \\
4 & $\begin{array}{c}\text { PtOEP-C6 ratiometric } \\
\text { oxygen sensor }\end{array}$ & 0.10 & 0.01 & This work \\
\hline
\end{tabular}


a

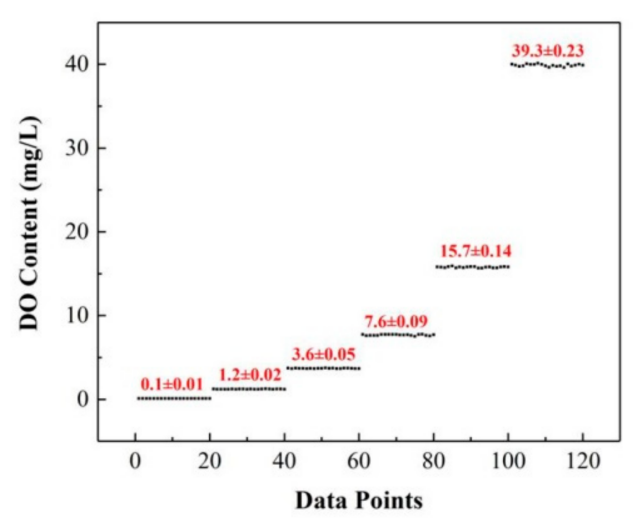

b

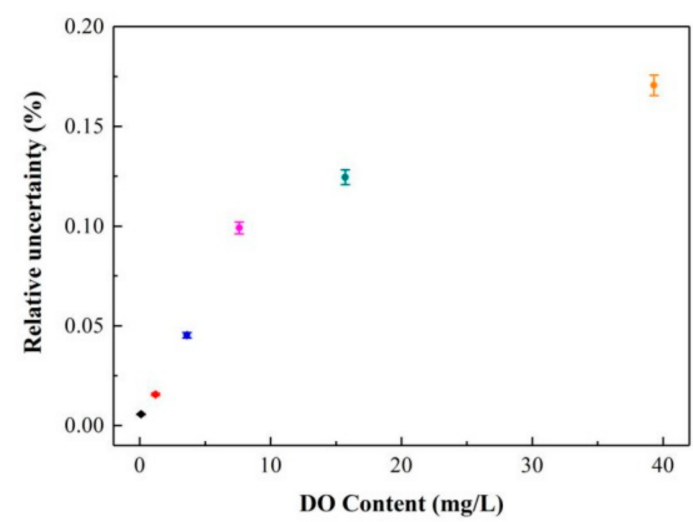

Figure 8. Performance of oxygen sensor: (a) Detection limit; (b) Relative uncertainty versus DO content.

The comparison results indicate that the ratiometric oxygen sensor in this study shows a lower detection limit and better detection accuracy. The variation in relative uncertainty with the DO content was mainly attributed to the concentration ratio of the two indicators. Consequently, the performance of the ratiometric oxygen sensor can be optimized by adjusting the amounts of PtOEP and C6, which possess other minimum detection limits and uncertainties for precise detection in different water environments.

\subsection{Investigation of DO Kinetic Process}

The ratiometric oxygen sensor was applied to the investigation of the kinetic process related to the variation of the DO content in water, which was obtained based on the following calibration equation by measuring the $O P$ values.

$$
[D O]=(O P-0.39) / 0.14
$$

Generally, the dissolution and diffusion of oxygen in water are geared to a dynamic reversible process. The saturated DO content in water under a certain condition can be obtained when the dissolution rate is equal to the diffusion rate, which is called the DO dynamic equilibrium. We selected deionized water saturated with nitrogen as the observation object to study the change in DO concentration at room temperature $(\mathrm{T}=292.15 \mathrm{~K})$. The variation of the measured DO content with time is shown in Figure 9. It can be seen that the DO content increases dramatically in the range of 1-3 $\mathrm{h}$, which indicates that the gaseous oxygen molecules in the air can be dissolved in water as well. With prolonged time, the change in the DO content slackens gradually and remains stable in the time range of 4.5-7 h. Finally, the measured DO content and time satisfy an exponential function correlation relationship (RMSEC $=1.08 \%$ ).

$$
[D O]=5.78 *[1-\exp (-1.32 * \mathrm{t})]
$$




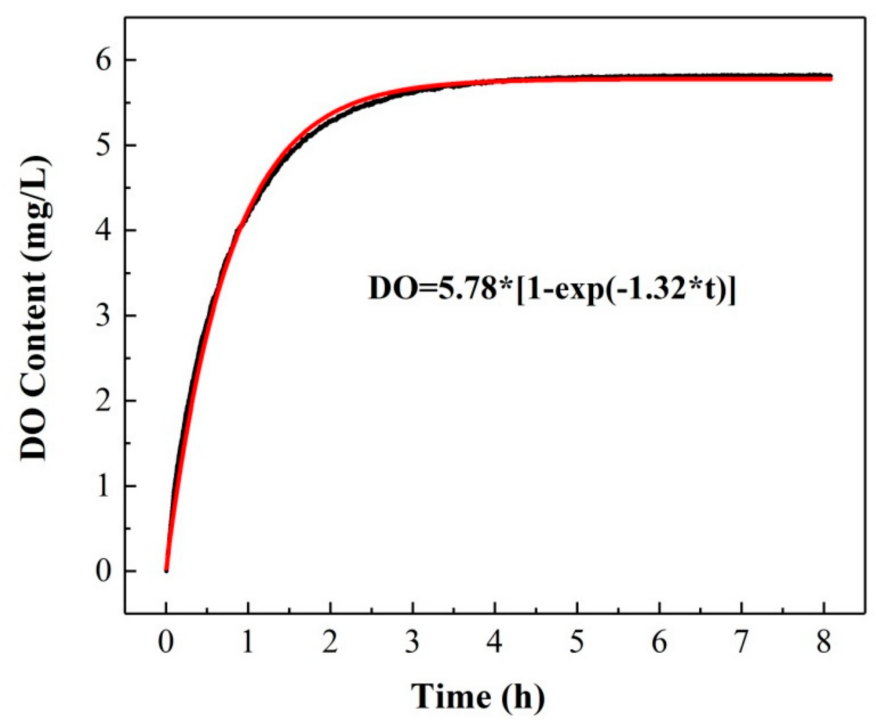

Figure 9. The variation of DO content; kinetic process.

Therefore, the saturation DO content under this condition was determined to be $5.82 \pm 0.02 \mathrm{mg} / \mathrm{L}$.

\section{Conclusions}

In summary, a ratiometric oxygen sensor based on the dynamic phosphorescence quenching mechanism with imbedded PtOEP and C6 in a poly (St-TFEMA) fluoropolymer film was developed for automatic DO content detection. Herein, PtOEP and C6 were chosen as the oxygen-sensitive and oxygen-insensitive indicators. $O P$ was defined as the ratio of the luminescence integral area of $C 6\left(\mathrm{~S}_{1}\right)$ to that of $\operatorname{PtOEP}\left(\mathrm{S}_{2}\right)$, which was only a function of the DO concentration. The changes in the luminescence intensity of the ratiometric sensing film with DO content were investigated, demonstrating that the calibration curve between the $O P$ value and $\mathrm{DO}$ content reveals a correlation expressed by a linear function. The automatic ratiometric oxygen detection system based on the Labview software was constructed utilizing a USB2000 spectrometer. The sensor can effectively eliminate external interference due to the variation and fluctuation of the excitation light intensity, and present good OP stability. The performance parameters of the ratiometric oxygen sensor were evaluated, and the detection limit was determined to be 0.10 (1) $\mathrm{mg} / \mathrm{L}$. Moreover, the oxygen sensor exhibits satisfactory reversibility, with a fast response time of $0.4 \pm 0.2 \mathrm{~s}$ and recovery time of $1.3 \pm 0.2 \mathrm{~s}$. Finally, the ratiometric oxygen sensor based on the $O P-\mathrm{DO}$ calibration equation was applied to the investigation of the kinetics causing the change in the DO content in water. It was found that the DO content and time were correlated, expressed by an exponential function, and the saturation DO content at $\mathrm{T}=292.15 \mathrm{~K}$ was $5.82 \pm 0.02 \mathrm{mg} / \mathrm{L}$, which appeared at $t=4.5 \mathrm{~h}$. Furthermore, the ratiometric oxygen sensor exhibits good detection accuracy and relative uncertainty in practical application. Consequently, since the DO content detection in water samples shows good accuracy, we believe that the ratiometric oxygen sensor can be extended to other application fields.

Author Contributions: Conceptualization, H.Z.; methodology, H.Z.; software, H.Z.; validation, H.Z.; formal analysis, H.Z.; investigation, H.Z.; resources, H.Z. and Z.Z.; data curation, H.Z.; writing-original draft preparation, H.Z.; writing-review and editing, H.Z.; visualization, H.Z.; supervision, H.Z. and Z.Z.; project administration, Z.Z.; funding acquisition, Z.Z. All authors have read and agreed to the published version of the manuscript.

Funding: This work was supported by the National Natural Science Foundation of China (Grant No. 81571720, 81530052, and 81727809).

Conflicts of Interest: The authors declare no conflict of interest. 


\section{References}

1. Wolfbeis, O.S. Luminescent sensing and imaging of oxygen: Fierce competition to the Clark electrode. BioEssays 2015, 37, 921-928. [CrossRef]

2. Misra, A.K.; Tiwari, P.K. A model for the effect of density of human population on the depletion of dissolved oxygen in a water body. Environ. Dev. Sustain. 2014, 17, 623-640. [CrossRef]

3. Lee, J.-H.; Lim, T.-S.; Seo, Y.; Bishop, P.L.; Papautsky, I. Needle-type dissolved oxygen microelectrode array sensors for in situ measurements. Sens. Actuators B Chem. 2007, 128, 179-185. [CrossRef]

4. $\quad$ Pang, H.-L.; Kwok, N.-Y.; Chow, L.; Yeung, C.-H.; Wong, K.-Y.; Chen, X.; Wang, X. ORMOSIL oxygen sensors on polystyrene microplate for dissolved oxygen measurement. Sens. Actuators B Chem. 2007, 123, 120-126. [CrossRef]

5. Wong, G.T. Removal of nitrite interference in the Winkler determination of dissolved oxygen in seawater. Mar. Chem. 2012, 130, 28-32. [CrossRef]

6. Zhang, D.; Kambe, S.; Tashiro, A.; Ohba, Y.; Mizuguchi, H.; Ito, K.; Kakizaki, S.; Okita, Y. Novel measuring and correction method of oxygen content $\mathrm{La}_{2}-\mathrm{xSrxCuOy}$ superconductors with the dissolved oxygen sensor. J. Ceram. Soc. Jpn. 2014, 122, 989-994. [CrossRef]

7. Wang, T.; Fan, S.; Erdmann, R.; Shannon, C. Detection of Ferrocenemethanol and molecular oxygen based on electrogenerated chemiluminescence quenching at a Bipolar Electrode. Langmuir 2013, 29, 16040-16044. [CrossRef] [PubMed]

8. Li, M.; Liu, W.; Correia, J.; Mourato, A.; Viana, A.; Jin, G. Optical and electrochemical combination sensor with poly-aniline film modified gold surface and its application for dissolved oxygen detection. Electroanalysis 2014, 26, 374-381. [CrossRef]

9. Xue, R.; Ge, C.; Richardson, K.; Palmer, A.F.; Viapiano, M.; Lannutti, J.J. Microscale sensing of oxygen via encapsulated porphyrin nanofibers: Effect of indicator and polymer "core" permeability. ACS Appl. Mater. Interfaces 2015, 7, 8606-8614. [CrossRef] [PubMed]

10. Michelucci, U.; Baumgartner, M.; Venturini, F. Optical oxygen sensing with artificial intelligence. Sensors 2019, 19, 777. [CrossRef] [PubMed]

11. Kwak, J.S.; Choi, Y.G. Oxygen sensitivity of photoluminescence intensity of Pt complex dispersed in fluorinated acrylate for pressure sensitive paint applications. Electron. Mater. Lett. 2014, 10, 991-995. [CrossRef]

12. Zhao, X.; Zheng, W.; Dong, D.; Jiao, L. Temperature effect on fluorescence of PtOEP embedded in sol-gel membrane used in oxygen sensor. Optik 2013, 124, 6799-6802. [CrossRef]

13. Chu, C.-S.; Lo, Y.-L. Optical fiber dissolved oxygen sensor based on $\mathrm{Pt}(\mathrm{II})$ complex and core-shell silica nanoparticles incorporated with sol-gel matrix. Sens. Actuators B Chem. 2010, 151, 83-89. [CrossRef]

14. Song, D.H.; Kim, H.D.; Kim, K.C. Dissolved oxygen concentration field measurement in micro-scale water flows using PtOEP/PS film sensor. Opt. Lasers Eng. 2012, 50, 74-81. [CrossRef]

15. Chu, C.-S.; Chuang, C.-Y. Ratiometric optical fiber dissolved oxygen sensor based on metalloporphyrin and CdSe quantum dots embedded in sol-gel matrix. J. Lumin. 2015, 167, 114-119. [CrossRef]

16. Chu, C.-S.; Chuang, C.-Y. Ratiometric optical fiber sensor for dual sensing of copper ion and dissolved oxygen. Appl. Opt. 2015, 54, 10659-10665. [CrossRef]

17. Koo, Y.-E.L.; Cao, Y.; Kopelman, R.; Koo, S.M.; Brasuel, A.M.; Philbert, M.A. Real-time measurements of dissolved oxygen inside live cells by organically modified silicate fluorescent nanosensors. Anal. Chem. 2004, 76, 2498-2505. [CrossRef]

18. Wang, X.-D.; Wolfbeis, O.S. Optical methods for sensing and imaging oxygen: Materials, spectroscopies and applications. Chem. Soc. Rev. 2014, 43, 3666-3761. [CrossRef]

19. Jiang, Z.; Yu, X.; Zhai, S.; Hao, Y. Ratiometric dissolved oxygen sensors based on ruthenium complex doped with silver nanoparticles. Sensors 2017, 17, 548. [CrossRef]

20. Chu, C.-S.; Lo, Y.-L. Ratiometric fiber-optic oxygen sensors based on sol-gel matrix doped with metalloporphyrin and 7-amino-4-trifluoromethyl coumarin. Sens. Actuators B Chem. 2008, 134, 711-717. [CrossRef]

21. Hussain, E.; Cheng, C.; Li, Y.; Niu, N.; Zhou, H.; Jin, X.; Kong, J.; Yu, C. Benzo [ghi] perylene \& coronene as ratiometric reversible optical oxygen nano-sensors. Sens. Actuators B Chem. 2019, 287, 27-34.

22. Wang, X.-D.; Chen, X.; Xie, Z.-X.; Wang, X.-R. Reversible optical sensor strip for oxygen. Angew. Chem. Int. Ed. 2008, 47, 7450-7453. [CrossRef] 
23. Zhao, H.; Zang, L.; Wang, L.; Qin, F.; Zhang, Z.; Cao, W. Luminescence ratiometric oxygen sensor based on gadolinium labeled porphyrin and filter paper. Sens. Actuators B Chem. 2015, 215, 405-411. [CrossRef]

24. Liu, T.; Zhang, X.; Zhang, H.; Zhao, H.; Zhang, Z.; Tian, Y. Method for monitoring singlet oxygen quantum yield in real time by time resolved spectroscopy measurement. Opt. Express 2020, 28, 25757-25766. [CrossRef] [PubMed]

25. Liu, T.; Zhang, H.; Zhao, H.; Zhang, Z.; Tian, Y. Excellent capacity of singlet oxygen generation by gadolinium labelled sinoporphyrin sodium. J. Lumin. 2020, 219, 116972. [CrossRef]

26. Feng, Y.; Cheng, J.; Zhou, L.; Zhou, X.; Xiang, H. Ratiometric optical oxygen sensing: A review in respect of material design. Analyst 2012, 137, 4885-4901. [CrossRef] [PubMed]

27. Lu, S.; Xu, W.; Chen, Y.; Jiang, Y.; Yao, Q.; Luo, F.; Wang, Y.; Chen, X. Soft template synthesis of honeycomb-like ratiometric oxygen sensitive polystyrene nanospheres and their application in anti-counterfeit authentication and food packaging dynamic indication. Sens. Actuators B Chem. 2016, 232, 585-594. [CrossRef]

28. Deng, M.; Qiao, Y.; Liu, C.; Wang, Z.; Shi, J.; Pan, T.; Mao, Y.; Mei, Z.; Huang, F.; Tian, Y. Tricolor core/shell polymeric ratiometric nanosensors for intracellular glucose and oxygen dual sensing. Sens. Actuators B Chem. 2019, 286, 437-444. [CrossRef]

29. Xue, R.; Behera, P.; Viapiano, M.S.; Lannutti, J.J. Rapid response oxygen-sensing nanofibers. Mater. Sci. Eng. C. 2013, 33, 3450-3457. [CrossRef]

30. Xia, T.; Jiang, L.; Zhang, J.; Wan, Y.; Yang, Y.; Gan, J.; Cui, Y.; Yang, Z.; Qian, G. A fluorometric metal-organic framework oxygen sensor: From sensitive powder to portable optical fiber device. Microporous Mesoporous Mater. 2020, 305, 110396. [CrossRef]

31. Xu, G.; Lu, M.; Huang, C.; Wang, Y.; Ge, S. Study on an oxygen sensing rhenium(I) complex with enlarged sensing/active area: Fabrication, photophysical parameters and molecular oxygen sensing performance. Spectrochim. Acta Part A Mol. Biomol. Spectrosc. 2014, 123, 369-375. [CrossRef]

32. Helm, I.; Jalukse, L.; Leito, I. A highly accurate method for determination of dissolved oxygen: Gravimetric Winkler method. Anal. Chim. Acta 2012, 741, 21-31. [CrossRef]

Publisher's Note: MDPI stays neutral with regard to jurisdictional claims in published maps and institutional affiliations.

(C) 2020 by the authors. Licensee MDPI, Basel, Switzerland. This article is an open access article distributed under the terms and conditions of the Creative Commons Attribution (CC BY) license (http://creativecommons.org/licenses/by/4.0/). 